\title{
Characterization of Ancient Cob Wall of Madagascar for Potential Green and Economical Construction
}

\author{
Andriamalala Anjaramanantenasoa Nirina Miraniaina ${ }^{1}$, Ratoarivelo Manitriniala ${ }^{1}$, Goodary Rajeshwar ${ }^{2}$, \\ Andriamahefa Augustin ${ }^{3}$ \\ ${ }^{1}$ Institut Supérieur de Technologie d'Antananarivo \\ RN2 - Ampasampito,101 Antananarivo, Madagascar. \\ miraniaina2@yahoo.fr;mratoarivelo@gmail.com \\ ${ }^{2}$ Université des Mascareignes \\ Avenue de la Concorde, Roches Brunes, Rose Hill, Mauritius. \\ rgoodary@udm.ac.mu \\ ${ }^{3}$ Ecole Supérieure Polytechnique d'Antananarivo \\ 101 Antananarivo, Madagascar \\ ingahmalagasy@gmail.com
}

\begin{abstract}
Earthen constructions have existed for thousands of years in the world. In Madagascar, remains of over 300 years of construction still exist today and are part of the «Malagasy » heritage. Currently, the construction methodology and the know-how around the constructions with cob are almost in-existent. The purpose of this research is not only to find the techniques to rebuild with raw earth and to reduce the carbon footprint in civil engineering in Madagascar, but also to provide an economic alternative to concrete constructions. Various samples have been taken and analyzed to determine the formulation of the «Malagasy » cob and to demystify the misleading idea that these types of constructions contain additives of animal origin. Building with earth will definitely reduce cost and maintain sustainability, and once the right composition is determined, it will be possible to provide various architectural designs with a life span of 50 to 100 years, depending on implementation techniques used. Finally, this will lead to the use of abundantly available material locally, hence reduce additional transportation and related costs, yielding recyclable and economical structures.
\end{abstract}

Keywords: Cob wall, carbon footprint, concrete, sustainable, green construction.

\section{Introduction}

Building materials in general include all components used in the field of civil engineering for construction purposes. Because of its abundance and accessibility in terms of cost, the earth material is the most used one, worldwide, Steve, 1997 [1].

Constructions with mud are among the oldest that our planet has known, Fabien Ginisty 2018 [2] Hamard E, Cazacliu B, Razakamanantsoa A, Morel J-C [9]. Their appearance in Madagascar cannot be dated with precision, but we find in historical documents from the era of King Andrianampoinimerina (1745-1810) who banned in his royal edict, constructions in barge or stone for people alive. There are many types of mud constructions in Madagascar and these include adobe construction. The latter is undoubtedly the most affordable and surpasses other techniques for many reasons. You just have to look at the remains of the past through the old buildings. Few mud or adobe constructions have survived the centuries to find themselves still intact today.

Oral traditions would indicate the presence of ovalbumin, cow dung or sap in the old constructions, but we will retain only the main constituent materials which are the earth and the plant fibers used to limit the cracks due to shrinkage. The ease of construction, combined with the ease of design have made the cob-wall, as a preferred one as compared to other techniques of construction with mud. It is a traditional technique that has been used for thousands of years and in all kinds of climates, Greer and Short, 1995, [3]. It is also known to be very weather-resistant because of its porous nature and it can withstand long periods of rain without losing its main propertied, Keefe et al., 2001 [4].

Unfortunately, the formulation of the cob has not been transmitted to current generations and the ancestral know-how for its implementation have also been lost. This is witnessed by the still visible constructions that still stand in excellent conditions.

To find the old formulation we will need to analyze different types of cob wall, but also other soils for comparison. 
This study focuses on the cob-wall in the highlands of Madagascar (the central part) whose altitude is above 800 $\mathrm{m}$. The main objective of this study is to present physicochemical results and the mineralogical characterization of cobwall and soils, with the specific objective of rediscovering it, and the demystification of the use of the various stabilizers and waterproofing agents of the time.

\section{Materials and methods}

The raw materials were sampled from the sites:

1- The residence of King Radama located in Manandrina, Antananarivo Avaradrano (GPS coordinates : Altitude 1316 m, Latitude S $18^{\circ} 48$ 37,40 " Longitude E $47^{\circ} 35^{\prime 24,14}$ ").

2- An old wall in Antanety, Antananarivo Atsimondrano (GPS coordinates : Altitude $1266 \mathrm{~m}$, Latitude S $18^{\circ}$ $55^{\prime} 52.97$ " Longitude E $47^{\circ} 29^{\prime} 01.25$ ")

These samples-cob were analyzed for their clay mineralogy (Chamayou and Legros, 1989; Brindley and Brown, 1980; Tan, 1991) [5]. The mineralogical composition was obtained from the X-ray diffraction (Bruker D8 advance diffractometer using $\mathrm{CuKa} 1$ radiation $(\lambda=1.54056)$ ) on powders obtained by grinding the original of cob or soils samples, then sieved at 40 microns for strips with fraction less than 40 microns (obtained by degressive sieving, to remove the quartz) treated with ethylene glycol. These methodology will also allow to determine the existence of swelling clays.

Thermogravimetric (ATG) and thermodifferential (ATD) analysis of the soil samples were realised using the mettler toledo TGA2.

The porosity of the solid samples was measured using a micromeritics autopore IV, mercury porometer with a lowpressure cycle $(0.0037 \mathrm{MPa})$ and a high-pressure cycle $(0.0007 \sim 413 \mathrm{MPa})$.

Particle size distribution as well as the plasticity of these building materials were also determined.

\section{Results and discussions}

\section{1. X-ray diffraction analysis}

Each clay family is characterized by a value of "d" of the plane (001). The main reflections $d(001)=26.5 \AA$; $(001)=12 \AA ; d(001)=8 \AA ; d(001)=27.7 \AA$ and $d(001)=18 \AA$ in Figure 1 indicate the presence of quartz, kaolinite, illite, feldspar and gibbsite, respectively, Brindley and Brown, 1980; Eslinger and Peaver, 1988, [6] in the sample.

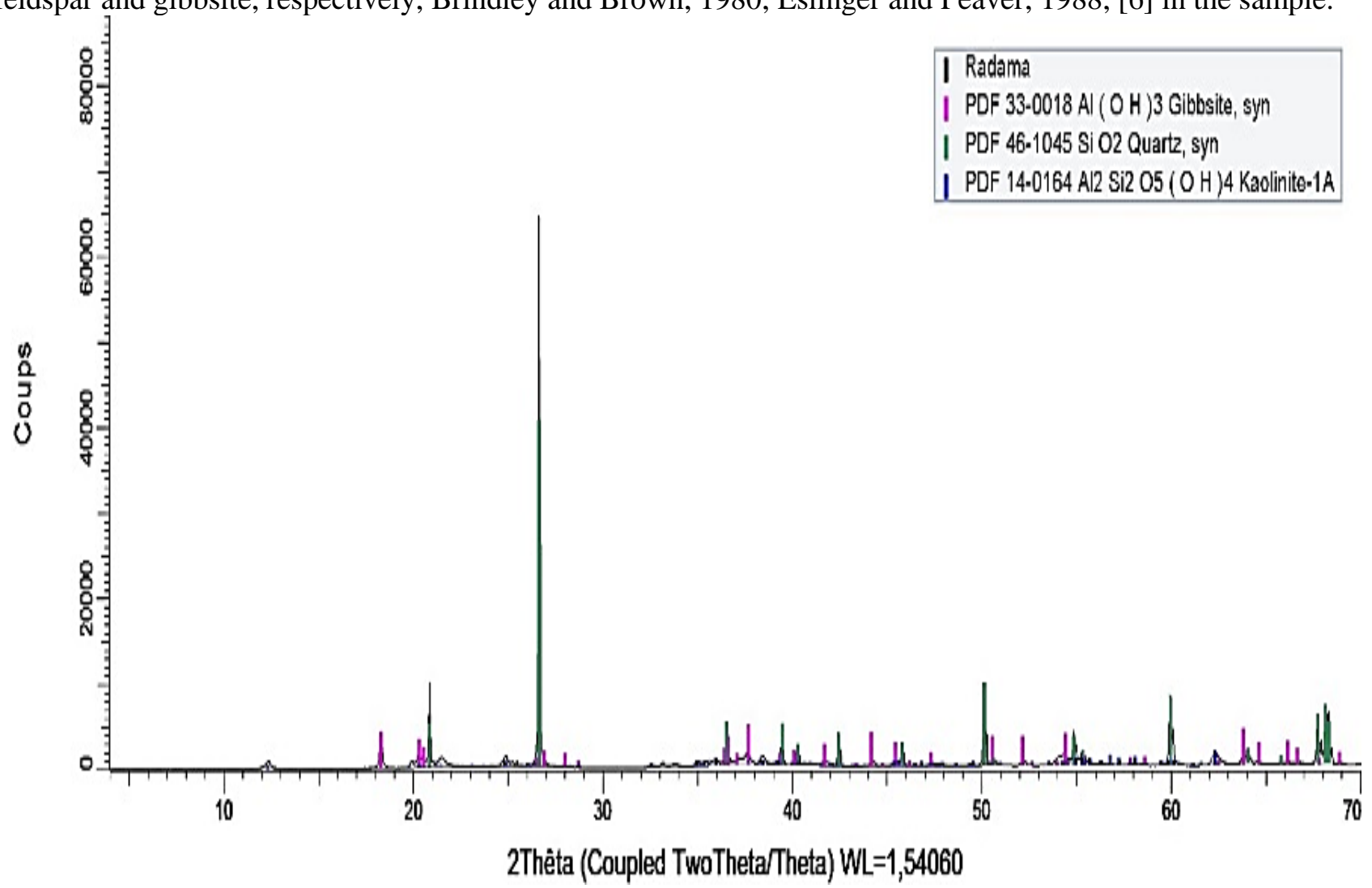

Fig. 1: Cob-wall Radama is characterized by the value of "d" of the plane (001). 
The results indicate that Radama and Antanety's samples have the same composition despite their age difference of about 3 centuries. The intensities of the peaks are somehow different, indicating different concentrations of minerals, but the composition is the same. The soils used for earth construction in ancient Madagascar are ordinary lateritic soils of the highlands.

The results of the XRD are distorted because of the "hyper-refraction" of quartz. Thus the withdrawal the refraction curves and flattening the values of the weakly refractory minerals. But here, the study focuses on the different types of clays and for this purpose the quartz minerals had to be withdrawn from the other minerals. Screening at $40 \mu \mathrm{m}$ eliminates quartz minerals and focuses on the $2 \AA$ to $40 \AA$ portion. The sieving result is first X-rayed, then it is treated with ethylene glycol, and again X-rayed. This process will eventually confirm the presence or absence of swelling clays. Figures 2 and 3 below, show the results of the X-ray diffractions on the samples under investigation.

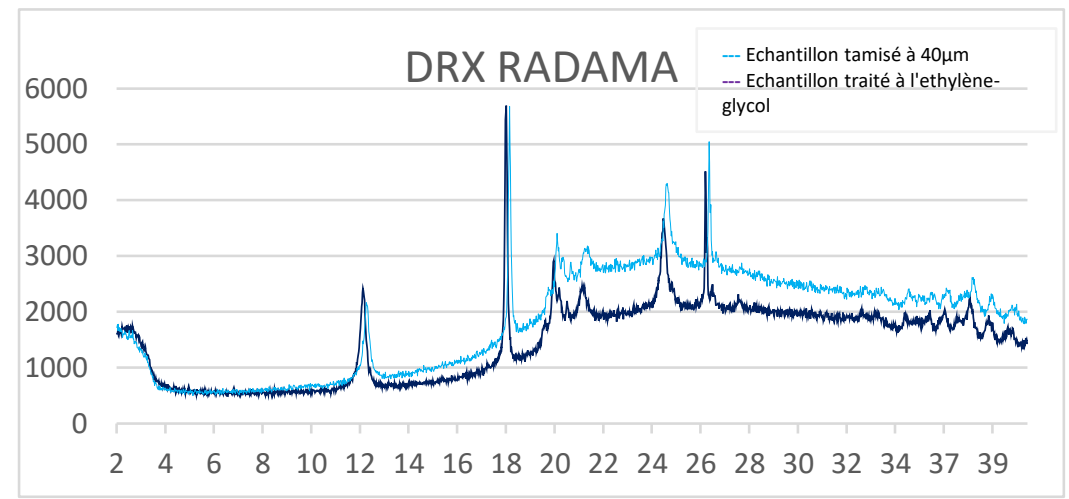

Fig. 2: Diffractogram of cob Radama.

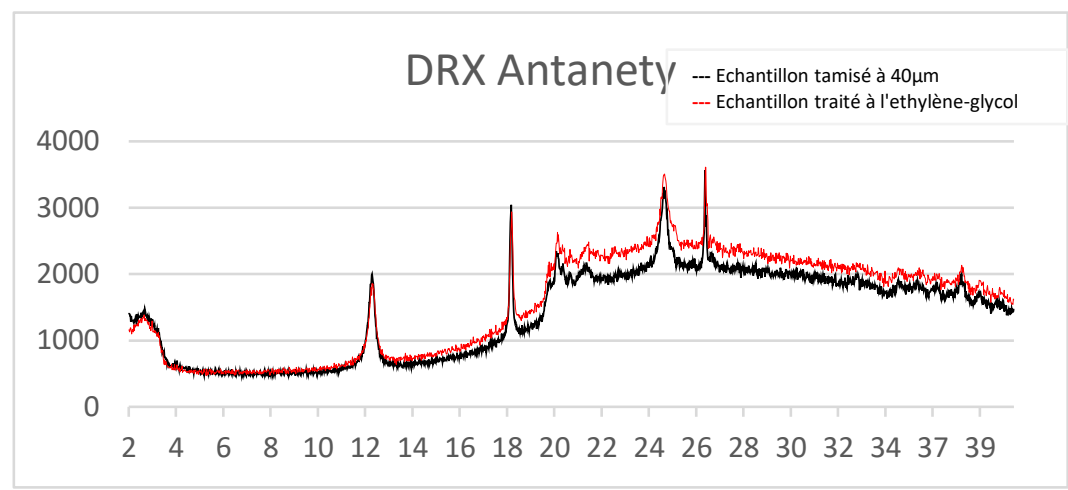

Fig. 3: Diffractogram of cob Antanety.

In figure 2 and figure 3 , the peak at $12.37 \AA$ and the absence of a peak around $7 \AA$ on the diffractogram of the clay fraction indicate the presence of kaolinite. This clay is not swelling because the treatment with ethylene glycol does not show a migration of peaks to the left. This partly explains the extreme durability of the earth constructions in Madagascar.

\section{2. Thermogravimetric analyzes of the cob}

Furthermore, two types of thermal analyses were performed on the above samples: differential thermal analysis (DTA) and thermogravimetric analysis (TGA).

The purpose of the ATD is to evaluate the energy released or absorbed by the material when it undergoes physical or chemical transformations during a thermal cycle; the ATG measures the mass variation of a sample during a thermal cycle.

This again partly explains the extreme durability of the constructions in Madagascar. 


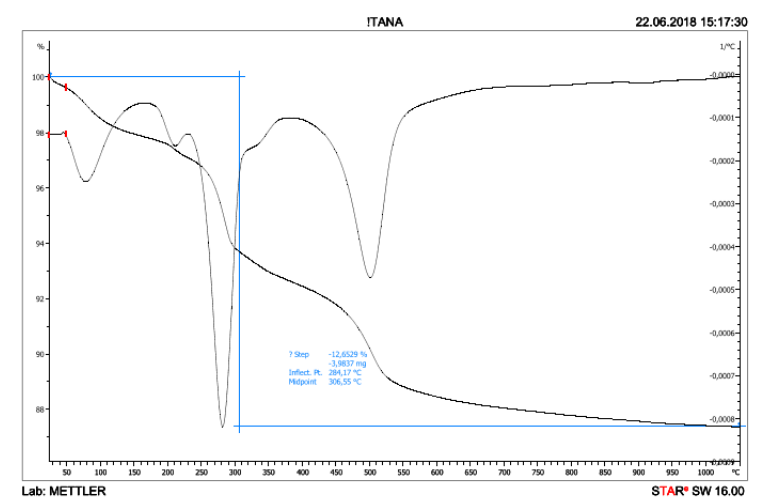

Fig. 4: Antanety

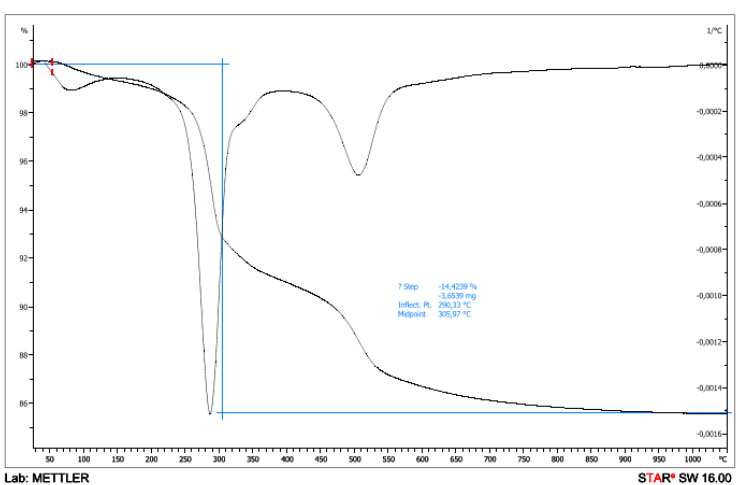

Fig. 5: Radama

Diagrams of the thermal analysis curves.

The thermal analyzes of the two samples indicate that the samples taken, have almost identical characteristics. The shape of the ATD and ATG curves in figures 4 and 5 above is typical compared to those obtained with materials containing clay minerals.

Three weight loss events are observed in the ATG and ATG curves at $60-70^{\circ} \mathrm{C}, 250-300^{\circ} \mathrm{C}$ and $500-520^{\circ} \mathrm{C}$, with total weight loss ranging from $12.65 \%$ to $14.43 \%$.

According to the ATD curves shown in figures 4 and 5 above, the first endothermic peak is linked with the evolution of water, physically adsorbed by the kaolinite particles. The second weight loss is due to the evolution of water resulting from the dehydration of the gibbsite and its subsequent transformation into an alumina transition phase.

The third weight loss is mainly associated with the dehydroxylation of kaolinite, which is transformed into metakaolinite. A large exothermic peak around $350{ }^{\circ} \mathrm{C}$, due to the decomposition of organic matter, was observed for all the samples analysed. In the present case, the weight loss in the temperature range of 250 to $300{ }^{\circ} \mathrm{C}$ is considered to be due to the dehydration of gibbsite, G. P. Souza, 2005 [7], whereas that in the range of 400 to $600{ }^{\circ} \mathrm{C}$ is due to the dehydroxylation of clay components.

\section{Conclusion}

Cross-referencing of the different test results is necessary to identify the malagasy material cob: the diffractogram, the thermogravimetry, the granulometry, the plasticity and the porometry.

The samples consist of fine porous plastic materials containing non-swelling silt and clay minerals, as well as organic materials. This characterization is one of the important and essential tools necessary for construction using earth. Indeed, it is a durable material, non-toxic, easy to use, ecological and very economical, Laurence Keefe 2005 [8], Myriam Olivier 2016 [10].

In future, this research should aim at optimization in the implementation process and improvement of the characteristics of the cob in Madagascar.

The results obtained in this research are in agreement with results published by other researchers in similar field (Brindley and Brown - 1980 and Eslinger and Peaver -1988, Souza - 2005) and they are deemed reliable.

\section{References}

[1] B. Steve, "Cob and Straw Bale Construction: The Perfect Marriage," Programme for Sustainable Living Fair, Montrose CA., 1997.

[2] Fabien Ginisty, Terre crue, l'autonomie sous nos pieds, dossiers l'âge de faire, 2018.

[3] M. Greer and D. Short, "Aspect of the Composite Behaviour of Cob. A Seminar Paper on Out of Earth II," University of Plymouth, England. (1995).

[4] L. Keefe, L. Watson and R. A. Griffiths, "A proposed diagnostic survey procedure for cob walls," Inst. Civil Engin. Struct. Build., vol. 146, pp. 57-65, 2001.

[5] Chamayou and Legros, 1989; Brindley and Brown, 1980; Tan1991, Les bases physiques, chimiques et minéralogiques de la science du sol. Presses Universitaires de France, Paris.

[6] Brindley and Brown, 1980; Eslinger and Peaver, Clay minerals for petroleum geologists and engineers, SEPM Short course 22. Soc. Economic paleontologists and mineralogists, Tulsa, USA, 1988. 
[7] G. P. Souza, S. J. G. Sousa, L. A. H. Terrones, J. N. F. Holanda, "Mineralogical analysis of Brazilian ceramic sedimentary clays used in red ceramic," 2005.

[8] Laurence Keefe, Earth Building: Methods and Materials, Repair and Conservation, 2005.

[9] E. Hamard, B. Cazacliu, A. Razakamanantsoa, Morel J-C, Cob, "A vernacular earth construction process in the context of modern sustainable building," Building and Environment, 2016.

[10] Myriam Olivier (CEREMA), Ali Mesbah (ENTPE), "Introduction à la construction en terre Document préparatoire au séminaire-formation," "Construire en terre crue de Guyane," Organisé par la DEAL Guyane, 2016. 